\title{
FRACTOGRAPHY OF FATIGUE CRACK GROWTH IN LOW-ALLOY STEELS
}

*J. Woodtli-Folprecht, M. Prodan** and J. C. Radon*** "Swiss Federal Laboratories for Materials Testing and Research, 8600 Dubendor.

$* *$ Imperial College of Science and Technology, London, England

ABSTRACT

growth characteristics of two low-alloy steels were The fatigue crack growth characteristics of cycling and of the fractograph studied in terms of low frequency tens. Three microstructural processes of part-through of were analysed: growth of shown that the formation of striations does not ductile tearing. It was shown sufficiently and other processes will have to describe fatigue crack ailed cyclic crack growth analysis.

KEYWORDS

Patigue crack growth; facets; striations; testing; micromechanisms of fatigue.

INTRODUCTION

The correct assessment of the propagation of microcracks formed in the plastic zone ahead of the crack tip is highly significant in the study of fatigue processes. The examination of separate micromechanisms relevant to cyclic crack propagation forms an essential part of our understande of of this subject. The fatigue crack growth characteristics of a range of Al-alloys were recently reported (1) and a number of individual mechesses operating in the cyclic deformation was alscussed. were found to be of particular importance for crack extension the observed and their combined effect was considered in the evaluater cleavage of the macroscopic crack growth behaviour. These protion of striations; and matrix, often environmenta

A similar approach may be adopted in the studimortance of these materials, structural steels. Because of the econack growth is necessary. The two a detailed understanding of fatis work have frequently been specified for structural steels chosen for this work have freques, such as offshore oi the fabrication of very large

platforms, where a high resistance to fat 
MATERIALS

The test materials selected were weldable structural steels, Table 1 . The tensile plate specimens were made from steel $\mathrm{BH} 43 \mathrm{~W}$ and the four-point ben the 5OD steel, consisting of ferrite and pearlite, is shown in Fig. 1. The microstructure and grain size of the second steel, $\mathrm{BH} 43 \mathrm{~W}$, was very similar in appearance. and grain size of the second steel, mean diameter of the grains was 10 to $15 \mu \mathrm{m}$.

SPECIMENS AND TEST PROCEDURE

Part-through cracks are frequently encountered in welded structures. Thes cracks are usually found in weld material or in HAZ, but their growth ma often be rather complicated. After the initiation in HAZ, the cracks propagate through the parent metal and, consequently, the analysis of the teast a duplex mater only parent material results are reported.

The fatigue tests were carried out on precracked plates provided with sharp, semi-elliptical surface notches. The dimensions of the tensile specimens were $20 \mathrm{~mm} \times 150 \mathrm{~mm} \times 800 \mathrm{~mm}$ with a central starter notch, $a=2 \mathrm{~mm}$ and $2 c=14 \mathrm{~mm}$. These were tested in a $1000 \mathrm{kN}$ Amsler loading frame at $6 \mathrm{~Hz}$ The four-point bend specimens were tested at $30 \mathrm{~Hz}$ in a specially built Dartec $200 \mathrm{kN}$ electrohydraulicmachine. The dimensions of the bend were $25.4 \mathrm{~mm} \times 111 \mathrm{~mm} \times 450 \mathrm{~mm}$ with a starter noth their longitudinal axes in $2 c=40 \mathrm{~mm}$. Both types of

After testing, the specimens were broken in liquid nitrogen and the fatigue After testing, the specimens were broken in liqu spacings were compared with fracture surfaces examine crack growth rates and plotted as functions of da/dN versus $\Delta K$

\section{CALCULATIONS OF CRACK GROWTH RATES}

The method for computing $d a / d N$ and $d c / d N$ involves fitting second-order polynomials to successive sets of measured $(N, a)$ and $(N, C)$ data points. $a, c$ and $N$ are the respective notations for crack depth, half crack length and cycle numbers.

The associated values of $\Delta K$ were computed using the Finite Element solution of Raju and Newman (6)

$F\left(\frac{a}{c}, \psi, \frac{a}{t}\right)=\frac{K \cdot \Phi}{\sigma \cdot \sqrt{\Pi a}}$

for the tensile plates. $F, \psi, t, K, \quad B$ and $\sigma$ are the respective notation for the tensile plates. $,, \psi, t, K, D$ and $\sigma$ are the respective notations intensity factor, elliptical integral second kind and normal stress. The $\Delta K$ intensity factor, elliptical the plates subjected to bending were estimated using the calibration function (7).

FRACTOGRAPHY

Figure 2 shows a number of crystallographic facets in the proximity of the notch base. These facets initiated along the suitably orientated slip planes; it is suggested that their star-like shapes indicate that they were by suden notch surface, probably not lower than $0.2 \mathrm{~mm}$ below the base of the notch.

Figures 3 and 4 show typical records of fracture surface topography near to the notch root. The fracture surface is very uneven and a high degree of irregularity in the growth of singular fatigue paths is clearly apparen Some of these paths are covered with very fine fatigue striations. The but fatigue paths are numerous and their distribution suggests a frequent, but localised, initiation of fatigue cracks. This behaviour is similar , and for materials at short crack lengths; for by Laird (3) and others (4), the BH $43 \mathrm{~W}, a=3 \mathrm{~mm}$ Fig. 4. As described by laile They are evenly spaced, striations in Fig. 5 are typically idual fatigue paths, which extend over an covering the whole sur af grains. With the increasing length of the fatigue area of a large number number crack, the denhological features, such as secondary cracks and dimples, is increasing.

wo types of secondary cracks can be observed. The large, widely open cracks were coarse, Fig. 6. These cracks (arrow 1) were often the result of a separation at the grain boundaries. However, similar coarse cracks were also found at the non-metallic inclusions, Fig. 7. All coarse cracks were independent of the overall crack propagation direction. The fine secondary cracks ran parallel to the fatigue striations, Fig. 6, arrow 2.

The depth of the secondary cracks depends mostly on their orientation. The coarse cracks situated on the grain boundaries ran generally to the depth of one grain, while the fine cracks were relatively shallow and not deeper than $5 \mathrm{\mu m}$. On the other hand, the secondary cracks which initiated at the nonmetallic inclusions, were comparatively deep and, depenaing on the orientation, they may follow the rows or inclusi main crack often occurs, as in Fig. 7 .

Fig, 8 shows a stepped facet in 5OD steel. This is a typical characteristic of fractures in the vicinity of non-metallic inclusions and also at lower values of $\Delta K$. Geometrically similar, but larger facets were observed on crossing the pearlite bands and the arrow 1 in Fig. 8 indicates the focus of an isolated burst, macroscopically recorded on the Ac potential drop record. Bursts of this type occurreasion (arrow 2).

In region II of the $d a / d N$ versus $\Delta K$ curve, a high density of the secondary In region II of the da/dn versus $\Delta K$ curve, a highs. This increasing crack cracks was obse previous observation on boiler steels (2). In general, the crack runs along the secondary cementite at the ferritic grain boundaries, or through the pearlitic colony, Fig. 9 . More importantly, the number of morphological features of tearing increases with the increasing $\Delta K$ value, and this was particularly obvious in the $\Psi=0$ airection.

CORRELATION OF MICROSCOPIC AND MACROSCOPIC CRACK GROWTH RATES

The experimental data obtained in fatigue tests can be conveniently compared with those derived from the measurement of striation spacing. An example of such correlations is shown in Fig. 10 for the tensile fatigue tests performed on steel $\mathrm{BH} 43 \mathrm{~W}$. The results presented include the upper transition,

AFR yor $3-Q^{*}$ 
together with a part of regions II and III. It will be observed that the striation spacings at the $\Delta K$ values of $20 \mathrm{MPa} \mathrm{m}^{\frac{1}{2}}$ agree substantially with the direct observation of the crack growt present results demons a good one-to-one correspondence between cycles presere there is an increas ed amount of ductile tearing, the striation spacing is significantly less than $d a / d N$. Cycling at low $\Delta K$ values may substantially decrease the number of striations. At still lower $\Delta K$, the continuum considerations of the crack growth will not be applicable.

\section{DISCUSSION}

It is commonly accepted that the fatigue crack propagation process can be simply described by a relationship of the form $d a / d N=$ a simple function of $\Delta K$, such as proposed by Rice (8) and others (9). However, crack growth rate measurements presented in this work indicate without doubt that, while this simple relation describes the crack growth in a limited $\Delta K$ region, usually defined as region II quite satisfactorily, it can not be used for all $\Delta K$ values indiscriminately. It has been observed that at very high $\Delta K$ values, the macroscopic growth is substantially higher than expected and, in fact, also higher than that calculated from the microscopic observations of the striation spacings. Conversely, the growth rate is very much lower than expected in fatigue at very low values of $\Delta K$. Such changes in the crack propagation rate were recently reported on boiler steel Hl described in (2) and also on a range of Al-alloys $(1,10)$.

The SEM observations discussed above indicate three modes of cyclic crack The values of $\Delta K$ and in the laboratory air environment propagation. At ver , the fatigue fracture surface showed predominantly at $30 \mathrm{~Hz}$ and $R$. facets. This regime is usually described as the threshold region, and the minimum value of $\Delta K_{T H}$, averaged for all thicknesses of the (n) revealed an almost entirely faceted fracture topography. These facets showed frequent steps and, in some cases, an appearance, albeit misleading, of striations. These facets, originally described by Forsyth (5) on smooth specimens, are mostly featureless, partly because of the extensive rubbing ff the fractured surfecs and partly due to the limited resolutions of the SEM.

The second regime, region II, begins at a $\Delta K$ value of $10 \mathrm{MPa} \mathrm{m}^{\frac{1}{2}}$ at a crack The second regime, region II, begins at a $\Delta K$ value of of the fracture surface was observed and typical fatigue striations noted. The crack growth rate can be represented by a crack propagation law of the form mentioned above. The striation spacing, measured by a well-established microscopic method, provided adequate crack growth rate data. In the present tests, the correlation between the striation spacing, optical surface crack length measurement and the electropotential AC method was excellent. The fatigue crack growth was transgranular, the path was relatively straight and the crack without any indication of significant branching; its direction was perpendicular to the applied stress.

At higher $\Delta K$ values from approximately $30 \mathrm{MPa} \mathrm{m}^{\frac{1}{2}}$ at $10^{-4} \mathrm{~mm} / \mathrm{cycle}$, the number of striations increased only slightly; in this region III, the crack extended by a combination of fatigue striations and microvoid coalescence. The proportion of dimples increased with the increasing value of $\Delta K$. A fully ductile fracture occurred at Kmax close to the value of $k_{c}$. range of $\Delta K$. Note that the change of $R$-ratio from 0.1 to these two steels. influence the fracture mode, at least not in these

\section{CONCLUSIONS}

A detailed analysis of fatique crack propagation in low alloy teels was presented.

ree microstructural proc crack growth; these are:

(a) Growth of crystallographic facets.

(b) Formation of striations,

(c) Ductile tearing.

REFERENCES (1) Rhodes, D., Nix, K.J., and Radon, J.C. (1982). Proc. 4th ECF Conf.',

(2) Woodtli-Folprecht, J. and Prodan, M. (1982). Proc. 4th ECF Conf.'

(Leoben) 480-487.

(3) Laird, C. (1966). ASTM STP 415, 131-168. Met., 30, 1549-1559.

(4) Nix, K.J., and Flower, H.M. (1982). Acta Met., 30, 1549anfield.

(5) Forsyth, P.J.E. (1961). Symp. on Crack Propagation, Cranfienics, 11, 817.

6) Raju, I.S. and Newman, J.C., (1979) (i Engng. Technical Notes: Stress

Koterazawa, R. and Minamisaka, S. (1977). Technical No in Bending, Intensity Factors of Semi-elliptical Surface Osaka University, Toyonaka/Japan, 915-921.

(8) Rice, J.R. (1967). Fatigue Crack Propagatioue and Microstructure. ASM

(9) Fine, M.E. and Ritchie, R.O.

(10) Rhotals Park, OH., J and Radon, J.C. (1984). Int. J. Fatigue, 6, $3-7$.

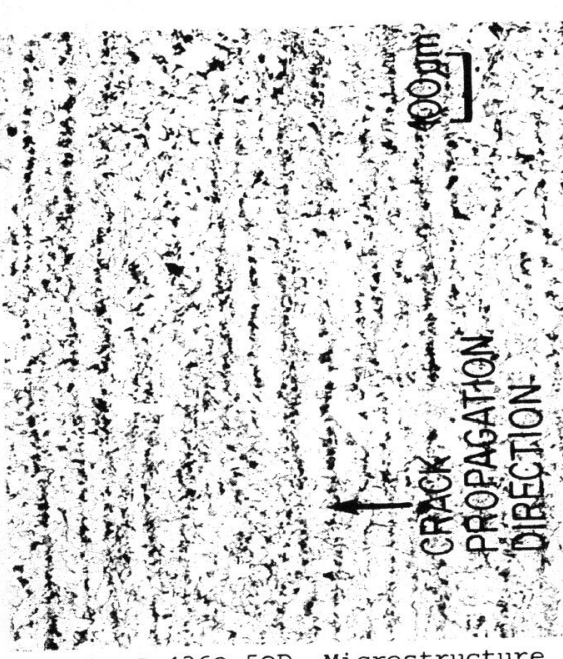

ig. I BS $4360-50 D$. Microstructure

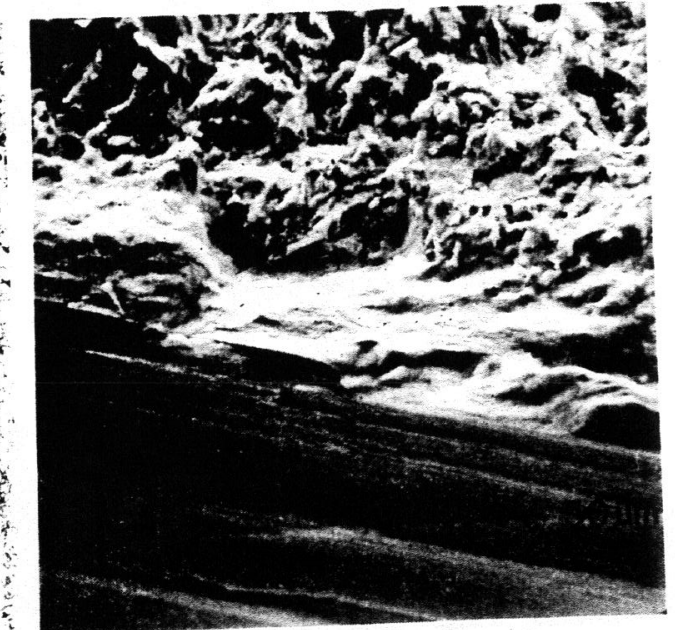

Fig. 2. Crystallographic facets 
Chemical composition and mechanical properties

\begin{tabular}{llllllllll}
\hline C & Si & Mn & P & S & Nb & V & Ni \\
\hline
\end{tabular}

BS4360-50 D

$\leqslant 0.18$

$\mathrm{BH}-43 \mathrm{~W}$

0.18

$0.32 \quad 1.38$

0.017

0.009

0.17

0.61

\begin{tabular}{ccccc}
\hline $\begin{array}{c}0,28 \text { Proof } \\
\text { stress } \\
\text { (MPa) }\end{array}$ & $\begin{array}{c}\text { Tensile } \\
\text { strength } \\
\text { (MPa) }\end{array}$ & $\begin{array}{c}\text { Elongation } \\
\mathrm{A}_{5}(\mathrm{8})\end{array}$ & $\begin{array}{c}\text { Impact } \\
\text { Strength } \\
(\mathrm{J})\end{array}$ \\
\hline $50 \mathrm{D}$ & 388 & 563 & 20 & $-10^{\circ \mathrm{C}}: 27$ \\
$43 \mathrm{~W}$ & 470 & 622 & 25 & $-20^{\circ} \mathrm{C}: 65$ \\
\hline
\end{tabular}
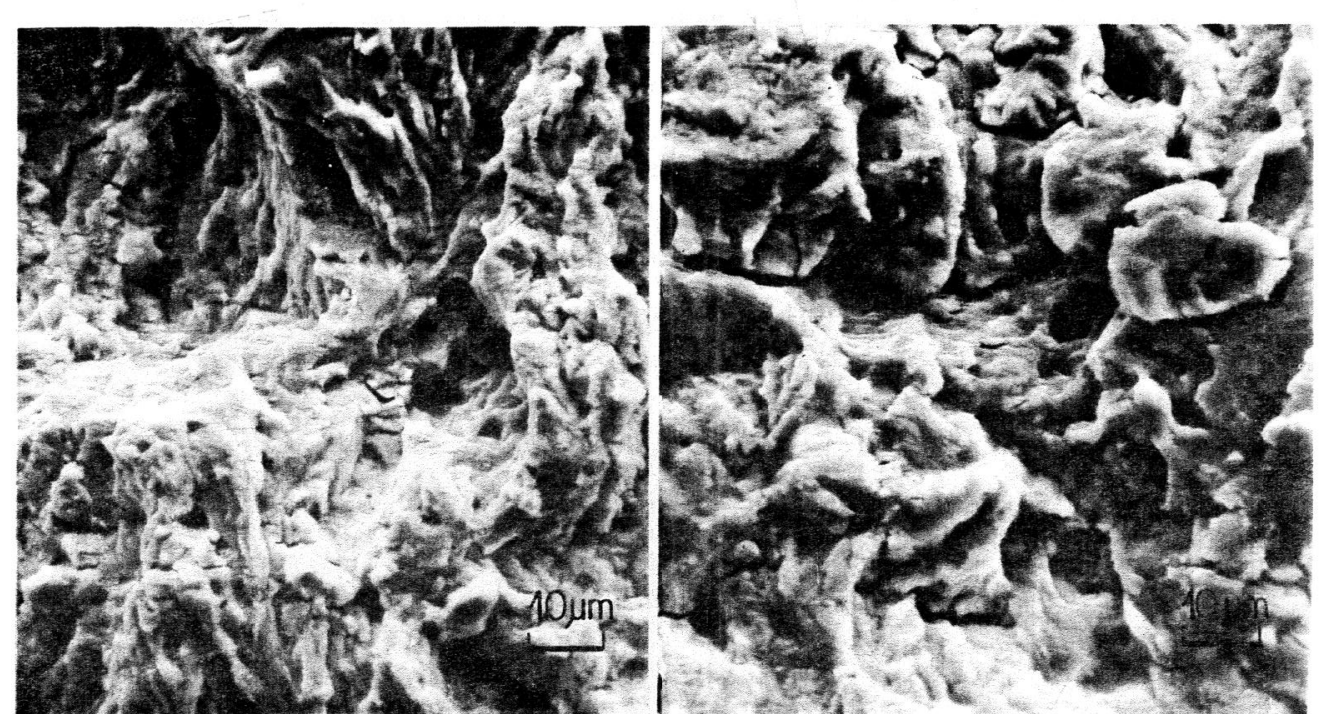

Fig. 3. 5OD steel. $a=7.5 \mathrm{~mm}$ Fig 4. BH $43 \mathrm{~W}$ steel. $a=3 \mathrm{~mm}$.
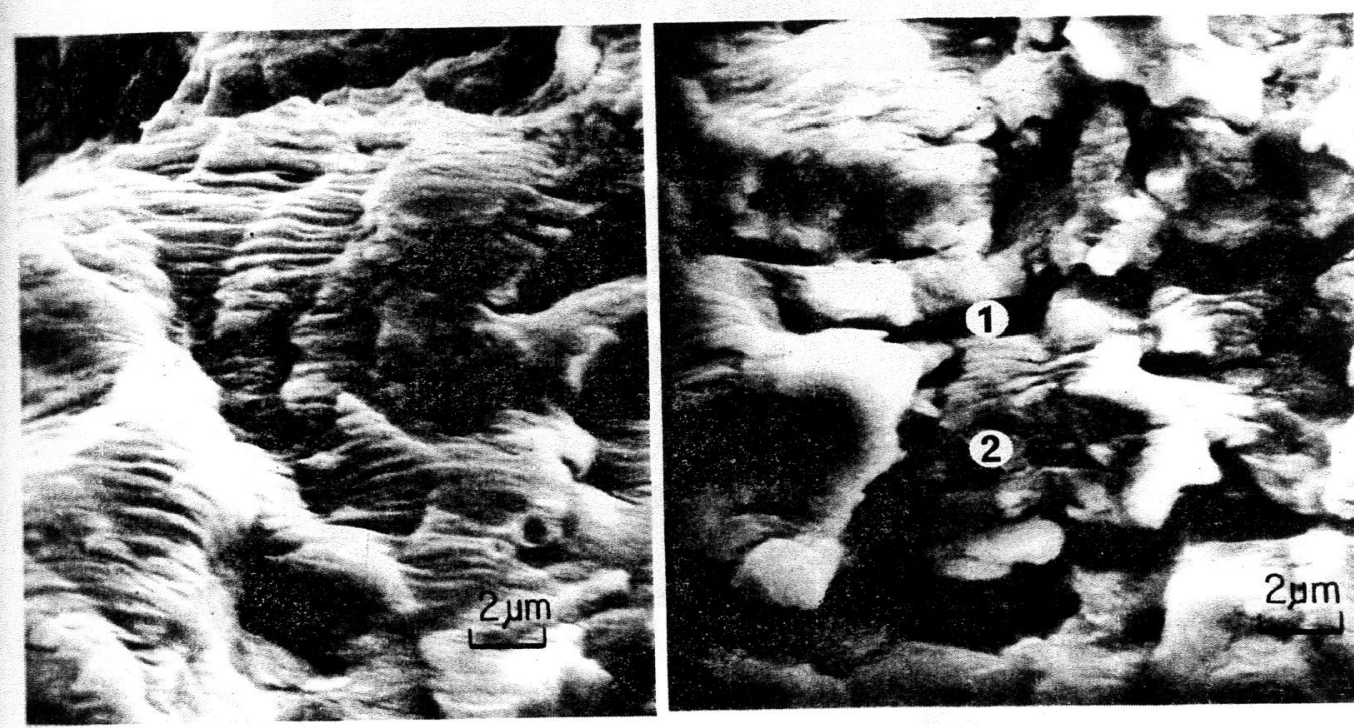

Fig. 5 Ductile striations

Fig. 6. Secondary cracks

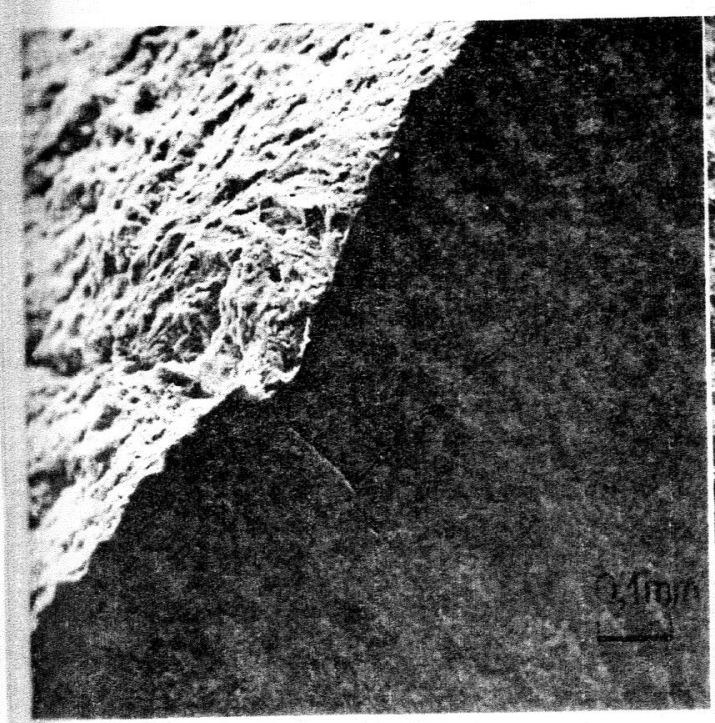

Fig. 7 Non-metallic inclusions

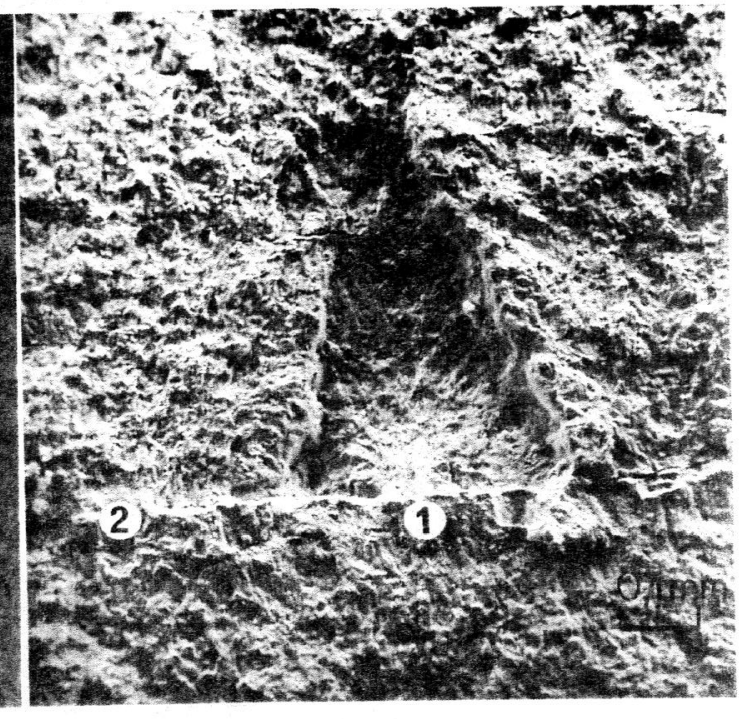

Fig. 8. A stepped facet 

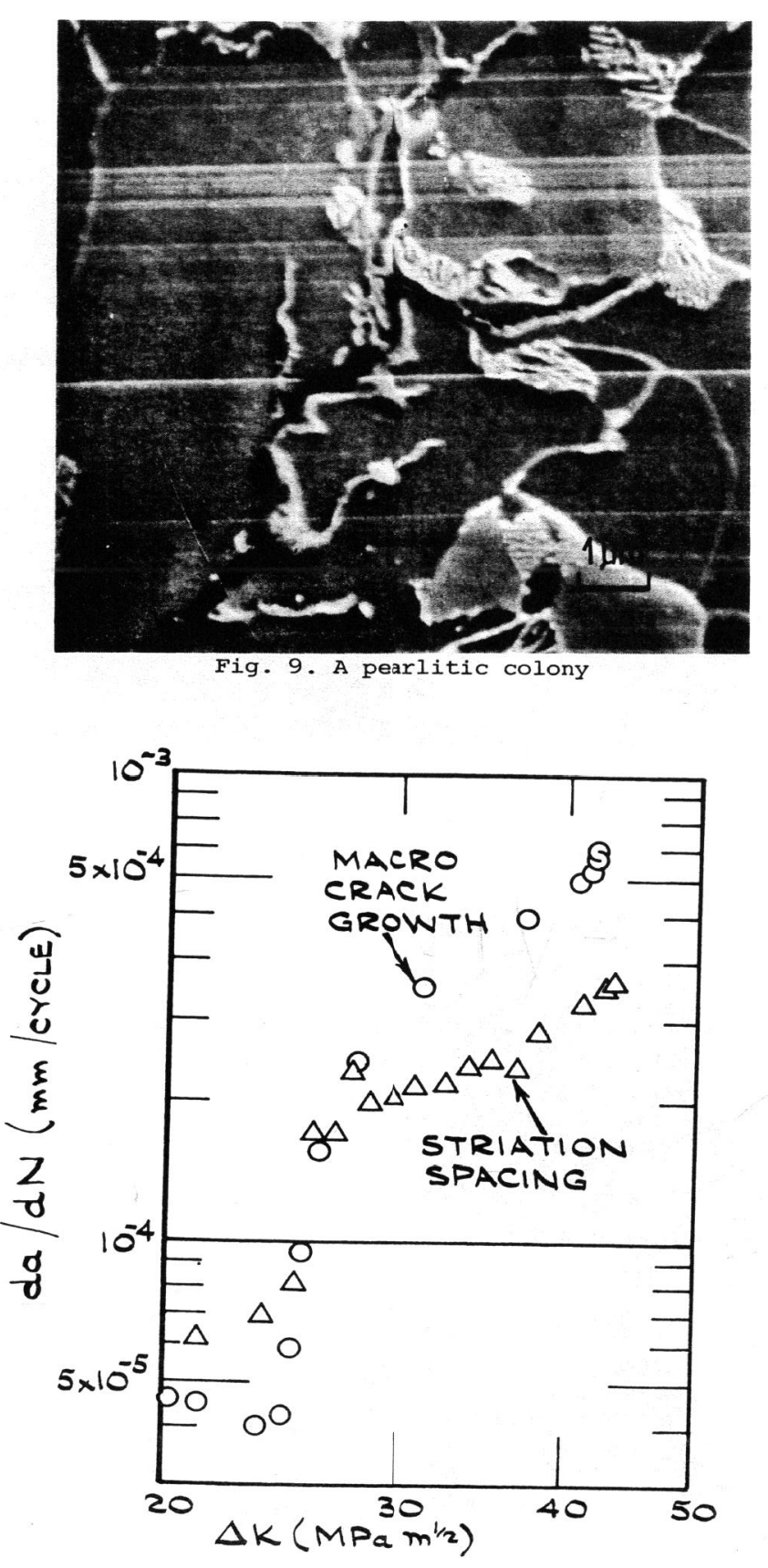

Fig. 10. 43 w steel. da/ dNvs. $\Delta K$ 